\title{
Hollow Pontic: Technique for Load Reduction on Edentulous Segment
}

\author{
${ }^{1}$ Shweta Dixit, ${ }^{2}$ Ajay Singh
}

\begin{abstract}
As in the field of dentistry, there have been several advances to provide a quality service. The occlusal forces applied to a fixed denture prosthesis (FDP) are transmitted to the supporting structures through the pontic, connectors and retainers. Span length, occlusion, bone loss, and quality of periodontium may be affected by the durability of an FDP and its abutment. Technique of hollow pontic is used for extensive loss of tissue in the pontic area, dense porosity free casting, porcelain cracking prevention on cooling. The present report depicts, such a case where a hollow pontic was given in a FDP.
\end{abstract}

Keywords: Bone loss, Esthetics, Hollow pontic, Pontic design

How to cite this article: Dixit S, Singh A. Hollow Pontic: Technique for Load Reduction on Edentulous Segment. J Health Sci Res 2015;6(1):22-24.

Source of support: Nil

Conflict of interest: None

\section{INTRODUCTION}

Basic design of hollow pontic was a three wall shell casting with the filling of acrylic resin in the hollow space. It was described in mid 1900s. ${ }^{1-3}$ Pontic is considered as foundation of abutments, since under occlusal load maximum stresses are concentrated on them. Selection of the right design of pontic can make a real difference between success and failure. The most important features of a pontic are that it has passive tissue contact with a convex, smooth fit surface and adequate embrasure space to facilitate cleaning. The use of hollow pontics, their designs and associated strengths have been studied by Shoher for over 20 years.

Area of severely loss of ridge and tissue is an indication for hollow pontic which results in the necessity to cast a large pontic. If the pontic is cast as one large volume of metal, this can result in significant casting porosity within the pontic or on the surface. Where there has been tissue loss, the technician may require extra guidance with the design of the final prosthesis. Gingival porcelain

${ }^{1}$ MDS Student, ${ }^{2}$ Head

1,2Department of Prosthodontics, Sardar Patel Institute of Dental and Medical Sciences, Lucknow, Uttar Pradesh, India

Corresponding Author: Shweta Dixit, MDS Student Department of Prosthodontics, Sardar Patel Institute of Dental and Medical Sciences, Lucknow, Uttar Pradesh, India, Phone: 8933063222, e-mail: sdixit5542@gmail.com which is pink in color to replace lost tissue often produces a better appearance than simply resorting to the use of large teeth. The basal contour of the pontic in particular has been modified to enhance esthetics and function in the anterior area.

The hollow pontic technique was developed to eliminate the inconsistencies and problems associated with conventional crown and bridge fabrication. Some of these are contraction cavities, non-homogeneous stresses, cracked connectors, cracking of porcelain, instability and differences in thermo expansion during firing between crown and pontic because of excessive weight when using precious metals. $^{2}$

Shoher and Whiteman ${ }^{4}$ found a $55 \%$ increase in load-bearing properties following the addition of porcelain to a perforated metal substructure compared to the substructure alone. An investigation by Rosenstein et $\mathrm{al}^{5}$ contradicted this study and found that a solid pontic without porcelain was significantly stronger than a metal framework with porcelain.

The objective of this technique is to produce crowns and pontics with 'balanced' volumes after casting, dense porosity free casting, porcelain cracking prevention and replacement of missing teeth without any further resorption. ${ }^{6}$

\section{CASE REPORT}

A 38 years old male patient reported to department of prosthodontics with a chief complaint of missing teeth in the lower anterior region and wanted replacement of the same (Fig. 1).

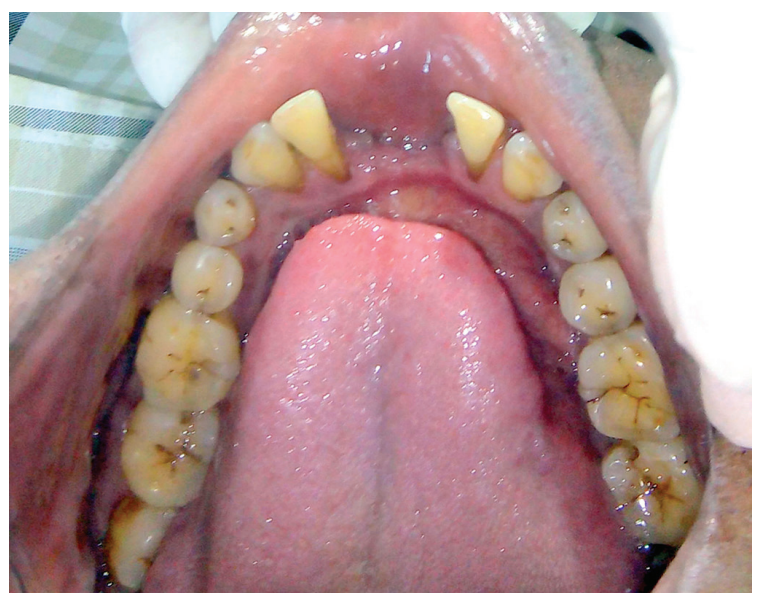

Fig. 1: Resorbed partially edentulous region 
On examination, it was found that partially edentulous area in the patient's mouth was resorbed and was not ideal for an esthetically good prosthesis.

Treatment plan included a fixed denture prosthesis with hollow pontic for partially edentulous segment to prevent further resorption of bone and casting porosity of metal.

Primary impression of maxillary and mandibular arch were made and with the help of face-bow transfer maxillary cast mounted on semiadjustable articulator. Mandibular cast mounted on its maximum intercuspal position with the maxillary cast. After tooth preparation (Fig. 2), final impression done with putty light body. Final cast mounted on semiadjustable articulator in its maximum intercuspal position with the maxilla.

\section{Lab Procedure}

The amount of wax removed was dictated by the actual size of the pontic. Anterior pontic was hollowed from the lingual aspect.

- The walls of the pontic were approximately $1.0 \mathrm{~mm}$ in cross-sectional thickness axially and 1.5-2.0 mm occlusally.

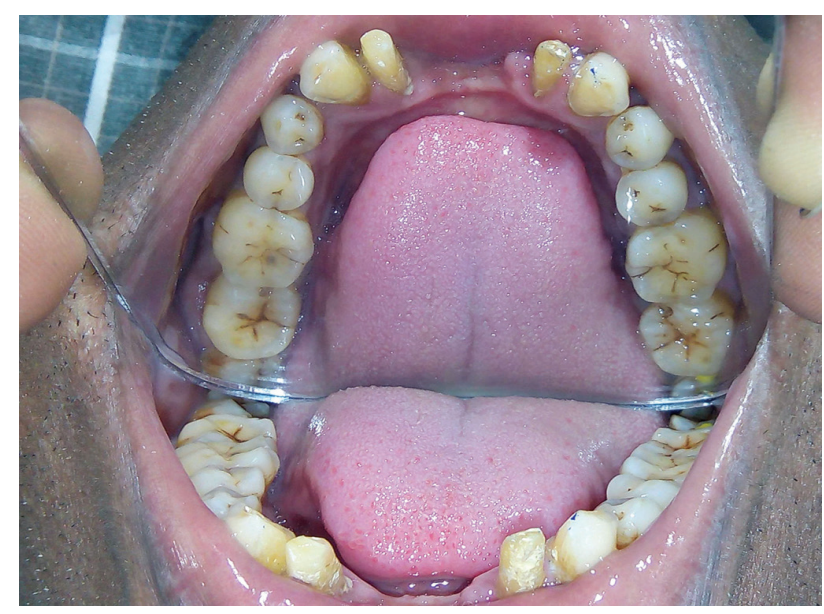

Fig. 2: Tooth preparation

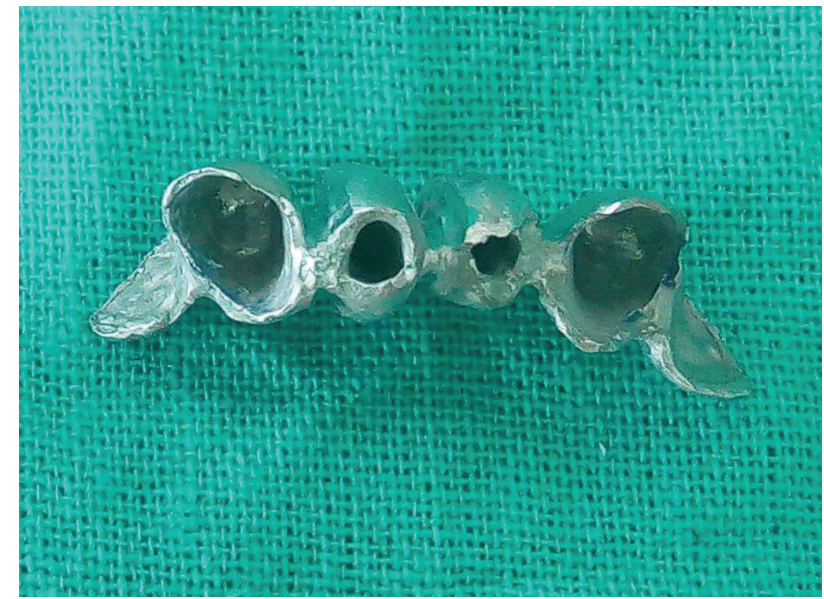

Fig. 4: Hollow pontic
- Placed a block-out material into the wax hollow pontic (investment material) (Fig. 3).

- Refined the pontic cap and pontic seating area with mirror image reverse bevels.

- Finished the investment material between the pontic cap (Fig. 4).

- Test for leaks of the cap by placing in a pressure pot at 20 psi for 15 minutes and evaluate for bubbles at the interface.

Metal trial and adjustment done (Fig. 5) followed by porcelain build up. Fixed partial denture was cemented using glass ionomer luting cement (Fig. 6). Postoperative instructions were given. Patient was recalled after 24 hours for postoperative adjustments. Patient was on recall after every 3 months for 1 year. Patient's response with the fixed partial denture was good and satisfactory (Fig. 7).

\section{DISCUSSION}

Pontics cannot considered as lifeless insert of prosthodontic material. It has now been proved that design of pontic may be the most important factor in preventing inflammatory reactions, not the material used in the pontic. The hollow pontic technique was developed to

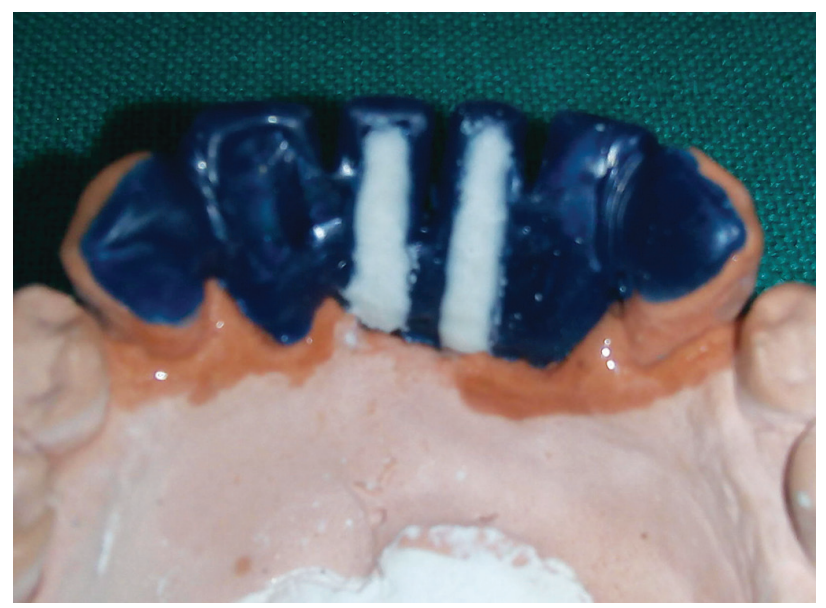

Fig. 3: Wax up and hollow space packed with investment material

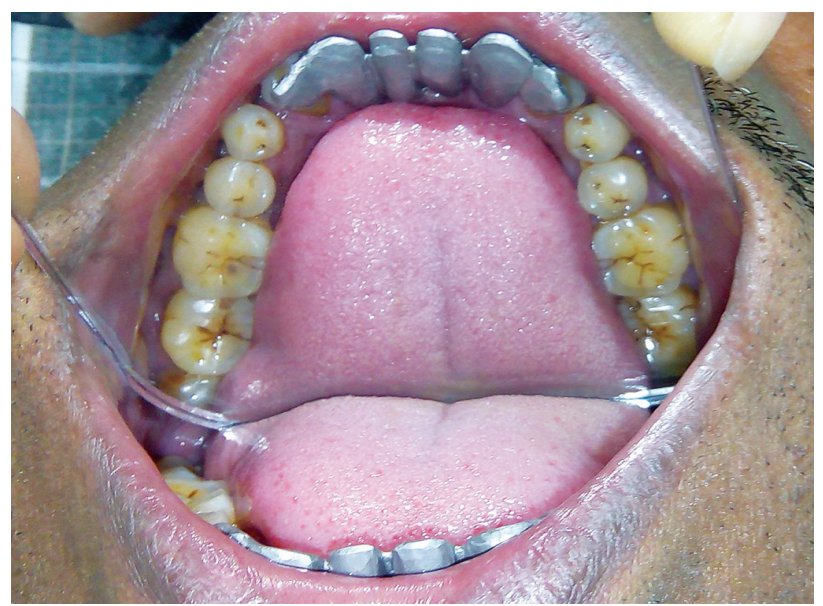

Fig. 5: Metal tri-in 


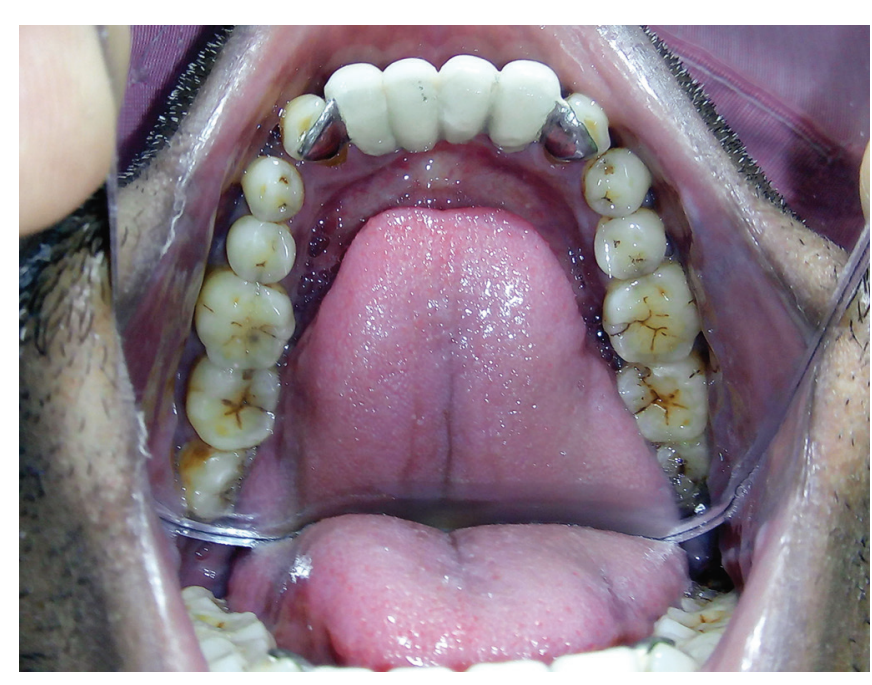

Fig. 6: Bridge with hollow pontic cemented with glass ionomer luting cement

eliminate the inconsistencies and problems associated with conventional crown and bridge fabrication. The objective of this technique is to produce crowns and pontics with less volume after casting. Few authors found no significant difference in the fracture resistance of the porcelain whether the pontic was solid or hollow. ${ }^{6}$ During solidification process of solid pontics, a contraction process is started which leads to metal being drawn away from the thin sectioned, adjacent crown to the centers of the solid pontic. Therefore, in cases involving large pontic construction surface defects, such as porosities and contraction cavities can be caused around the connection of the sprue to the pontic. Hollow pontic wax units provide contraction free and stress free metal sub frameworks. As the volumes of the cast crowns and pontics are well balanced, thermo expansion and many other problems disappear as well as reducing $58 \%$ of the metal used for pontics. Hollow pontics are an excellent candidate for the pressible ceramic technique. In a situation where a metal sub frame is going to be used as in the (PFM) technique certain precautions should be taken. The finish line should be placed at the joint of the axial walls with the shoulder. This allows for butt joint ceramic margins, and prevents metal showing through and contacting the oral tissues. Semi-precious, precious alloys and nonprecious metals can be used with pressible ceramics, however, we must respect the coefficient of the thermal expansion and make sure that there is a compatible factor at work in order for success. The wax up can be done in the cut back method or for full contour. This depends on the ensuing technique of layering or external staining. The lost wax method incorporating hollow pontics ensures absolutely no porosities and zero shrinkage of the pressed ceramic restoration. In the traditional method, the hollow pontic

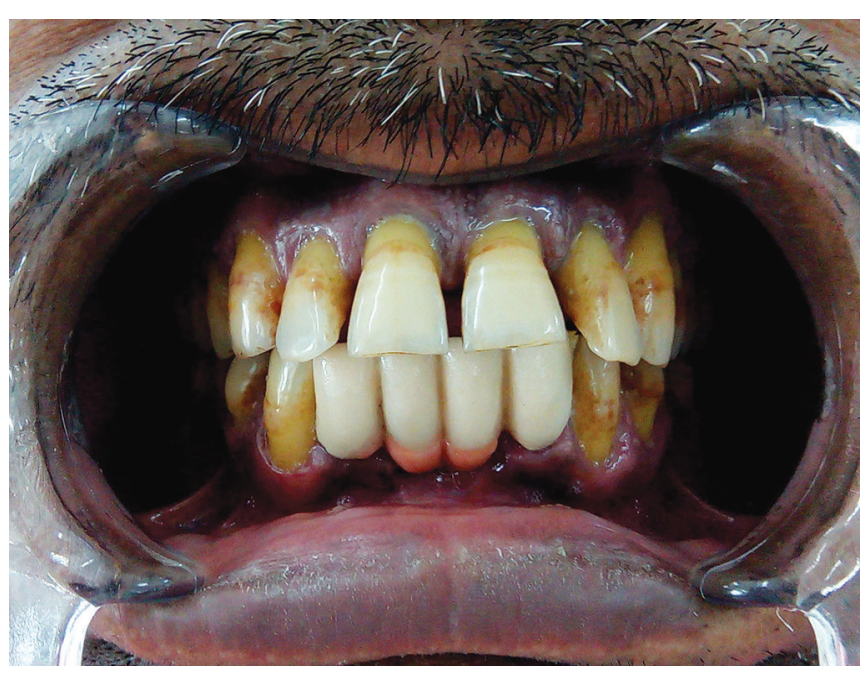

Fig. 7: Final prosthesis

usually is filled and baked before applying the opaque. ${ }^{6}$ There is also a method where rods of varying size of ceramic, using opaque and dentin are baked before and inserted into the hollow pontic at the wax up stage and cast directly to the metal. This saves time for the ceramist to fill the hollow space.

\section{CONCLUSION}

Load application when using hollow pontics on edentulous area is very less in comparison to other conventional pontic design. A good prosthesis should be functional, esthetic and retentive, and it should not harm oral anatomical structures, i.e. oral mucosa and edentulous alveolar ridge. Hollow pontic reduces the load as resorbtion of bone is less. Due to resorbtion of ridge, application of large hollow pontic is required with gingival porcelain for esthetic purpose. The presented case depicts such a design where a FDP with a hollow pontic was given with optimum success.

\section{REFERENCES}

1. Tamarin AH. The art in casting a hollow pontic. J Am Dent Assoc 1958 Jan;56(1):97-99.

2. Evenson RA. Apparatus for making pontic cores. US Patent number 3,661,198; May 9, 1972.

3. Tennyson PC. Tooth replacement assembly and method. US Patent number 5,458,489; Oct 17, 1995.

4. Shoher I, Whiteman AE. Reinforced porcelain system: a new concept in ceramometal restorations. J Prosthet Dent 1983 Oct; $50(4): 484-492$.

5. Rosenstein HE, Myers ML, Graser GN, Jarivs RH. Comparison of compressive strength of solid and hollow pontic designs for ceramometal fixed partial dentures. J Prosthet Dent 1987 Jun;57(6):693-696.

6. Gary DB. The application of hollow pontics in fixed prosthodontics: a laboratory perspective. Quintessence Dent Technol 1992;15(1):111-117. 